\title{
Article \\ Predictive Validity of the Single Leg Hamstring Bridge Test in Military Settings
}

\author{
Primož Pori ${ }^{1}$, Bogdan Kovčan ${ }^{2}$, Janez Vodičar ${ }^{1}$, Edvin Dervišević ${ }^{1}$, Damir Karpljuk ${ }^{1}$, Vedran Hadžić ${ }^{1}$ (D) \\ and Jožef Šimenko ${ }^{3, *}$ (D) \\ 1 Faculty of Sport, University of Ljubljana, 1000 Ljubljana, Slovenia; primoz.pori@fsp.uni-lj.si (P.P.); \\ Janez.Vodicar@fsp.uni-lj.si (J.V.); Edvin.Dervisevic@fsp.uni-lj.si (E.D.); Damir.Karpljuk@fsp.uni-lj.si (D.K.); \\ Vedran.Hadzic@fsp.uni-li.si (V.H.) \\ 2 Slovenian Armed Forces, 1000 Ljubljana, Slovenia; bogdan.kovcan@gmail.com \\ 3 Essex Pathways Department, University of Essex, Colchester CO4 3SQ, UK \\ * Correspondence: j.simenko@essex.ac.uk
}

check for updates

Citation: Pori, P.; Kovčan, B.; Vodičar, J.; Dervišević, E.; Karpljuk, D.; Hadžić, V.; Šimenko, J. Predictive Validity of the Single Leg Hamstring Bridge Test in Military Settings. Appl. Sci. 2021, 11, 1822. https://doi.org/ 10.3390/app11041822

Academic Editor: Filipe Teixeira-Dias

Received: 13 January 2021

Accepted: 11 February 2021

Published: 18 February 2021

Publisher's Note: MDPI stays neutral with regard to jurisdictional claims in published maps and institutional affiliations.

Copyright: (c) 2021 by the authors. Licensee MDPI, Basel, Switzerland. This article is an open access article distributed under the terms and conditions of the Creative Commons Attribution (CC BY) license (https:// creativecommons.org/licenses/by/ $4.0 /)$.

\begin{abstract}
The hamstrings are biarticular muscle group that plays an important role in the occupational performance of military personnel. The single leg hamstring bridge test (SLHBT) could be a good test to screen military personnel performance. The aims of our study were to assess the reproducibility of the SLHBT in the military population and to use receiver operating curve (ROC) analysis to examine the ability of the SLHBT to discriminate between soldiers with poor and good baseline fitness. A cross-sectional study was performed on 201 male members of the Slovenian Armed Forces (SAF). They undertook army physical fitness testing (APFT) and functional physical fitness testing (FPFT), which included the SLHBT. The SLHBT showed acceptable reproducibility in a military setting and had moderate predictive validity to discriminate between soldiers with poor and good overall physical fitness performance using a cut-off value of 20 repetitions. In conclusion, the SLHBT could be a good candidate test for the military population as the ROC analysis showed the ability of the SLHBT to discriminate between soldiers with poor and good baseline fitness. The SLHBT represents a simple and affordable test that can be used to evaluate performance and form preventive guidelines for military personnel.
\end{abstract}

Keywords: hamstrings; screening; field test; training; symmetry; army

\section{Introduction}

The hamstrings are an important biarticular muscle group that concentrically extend the hip, flex the knee, and participate in tibial rotation [1]. The hamstrings also eccentrically control knee extension. The rapid force capacity of this muscle group plays an important role for running acceleration performance [2], while poor hamstring flexibility (as measured by a sit-and-reach test or active straight leg raise) has been shown to influence posture, causing posterior pelvic tilt [3], and is associated with an increased risk for musculoskeletal injury (MSKI) [4]. In military forces, the risk of injury for males with both higher and lower levels of hamstring flexibility was reported to be more than twice that of those with 'average' flexibility [5,6]; therefore, the need to maintain moderate hamstring flexibility in special military groups was highlighted [7]. With this in mind, strengthening of the hamstring muscle should form an important part of training programs in military settings [8,9].

Different hamstring strengthening exercises are frequently used $[10,11]$ in general strength and conditioning (e.g., Nordic hamstring exercise, seated and prone leg curl, supine sliding leg curls, glute-ham raise, razor curl, $45^{\circ}$ hip extension from Roman chair, bilateral and unilateral stiff leg dead lift and Romanian dead lift, supine bridges, good morning exercise, kettlebell swing, hip thrusts, squats, leg press, lunges, hip hinge, singleleg bent-knee bridge, single leg straight knee bridge, single leg hamstring bridge (SLHB) and leg curl). However, their usage in military strength and conditioning training practice 
is not well known and data about hamstring strength in the military population is scarce (for example, the search string "hamstring strength" AND "military" returns only 18 items on PubMed, with only seven papers on military topics).

Although isokinetic dynamometry is the gold standard for hamstring strength testing [12], it has several limitations in regard to cost-benefit ratio, ecological validity (as it is a laboratory test), and the lack of significant associations with hamstring injury risk [13]. Handheld dynamometers can also be used to measure hamstring isometric strength [14-16], while some specific devices have been developed to measure eccentric hamstring strength $[17,18]$. Freckleton et al. [19] developed a simple field test for hamstring function [19] called the single leg hamstring bridge test (SLHBT). In this test, the individual lies down on the ground with one heel on a box that is 60 centimetres high (knee flexed to approximately $20^{\circ}$ and hip flexed to approximately $45^{\circ}$ ). The individual is then instructed to push down through the heel to lift their bottom off the ground while holding their arms crossed over their chest. Studies have shown that during the single-leg bridge, there is high hamstring and gluteal activation. However, considering the flexed position of the knee during this exercise, this exercise is usually considered as hamstring dominant. Additionally, gluteus maximus and medius weakness in combination with high hamstring activation may lead to the diminished contribution of this exercise to gluteal strengthening [20]. For these reasons, the authors of the test have added a descriptive hamstring bridge to this test, indicating its primary role during the test/exercise execution.

The baseline fitness of military personnel is usually tested using the army physical fitness test (APFT; trunk raises, push-ups, and a two-mile run) [21]. With an extension of military occupational demands, the APFT is usually complemented by additional functional physical fitness tests (FPFT) [22]. An appropriate test for hamstring strength should have: (1) good ecological validity (simple to perform on large samples; good cost-benefit ratio; not time-consuming); (2) good reproducibility and reliability; and (3) an ability to discriminate between soldiers with different baseline fitness. We believe that the SLHBT could be a good candidate test that meets these criteria, and therefore the aims of our study were to assess the reproducibility of the SLHBT in the military population and to use receiver operating curve (ROC) analysis to examine the ability of the SLHBT to discriminate between soldiers with poor and good baseline fitness.

\section{Materials and Methods}

\subsection{Experimental Approach to the Problem}

We carried out a cross-sectional study on 201 male members (age: $31.4 \pm 6.1$ years; height: $181.7 \pm 6.5 \mathrm{~cm}$; weight: $87.3 \pm 10.8 \mathrm{~kg}$; body mass index (BMI): $26.4 \pm 3 \mathrm{~kg} / \mathrm{m}^{2}$ ) of the Slovenian Armed Forces (SAF) within the research project registered at ClinicalTrials. gov (accessed on 17 February 2021) under the identifier NCT03415464. During the primary study, soldiers $(\mathrm{N}=181)$ underwent APFT and functional physical fitness testing (FPFT), which included but was not limited to the SLHBT. To investigate reproducibility, a smaller subgroup of soldiers $(\mathrm{N}=22)$ that did not participate in the primary study additionally performed the SLHBT twice in the period of one week in a test-retest manner without specific hamstring training between the two testing sessions. ROC analysis was carried out on our primary dataset $(\mathrm{N}=181)$ where the objective measure for good to excellent fitness was an APFT passing score $>4$ (explained below), while APFT scores of $<4$ were arbitrarily defined as poor to moderate baseline fitness. In the ROC analysis, the weaker leg's SLHBT value was used (e.g., the leg with which the soldier performed fewer repetitions $d$ the test).

\subsection{Subjects}

The Faculty Ethical Board (No. 454/2017) and the Headquarters of the SAF (No. 6301/2016-3) approved the study. During the study, the principles outlined in the Declaration of Helsinki were followed. This was a cross-sectional study, and therefore it has limitations in relation to sample representativeness. According to public data from the Slovenian Ministry of Defence, the SAF has 5734 active male members (representing $84 \%$ of all active 
members). The sample that participated in our study represents $3.2 \%$ of the total male population. Upon recruitment, all subjects signed an informed consent form to participate in the study voluntarily. At the time of testing, all soldiers were free of acute injuries and did not report any current pain in the musculoskeletal system.

\subsection{Army Physical Fitness Testing (APFT)}

Baseline fitness testing included APFT and functional testing (see below). APFT testing included 2 min push-ups, 2 min sit-ups, and a $3.2 \mathrm{~km}$ run [21].

\subsubsection{Sit-Ups}

Participants were in the supine position with feet $\leq 30 \mathrm{~cm}$ apart and knees flexed to $90^{\circ}$, and were instructed to maintain heels in contact with the ground throughout the test with the help of another participant's ankle support. Participants raised the upper body forward until the neck's base was at least above the base of the spine, and then began lowering until the shoulder blades contacted the ground. Repetitions were not counted if the vertical position was not reached, fingers did not remain interlocked behind the head, momentum was used to assist in raising the upper body, or knees exceeded $90^{\circ}$. The up position was the only authorized rest position; thus, if participants rested in the down position or assisted the rest with hands or elbows, the test was terminated. The number of successfully completed repetitions in the allotted $2 \mathrm{~min}$ was recorded [23].

\subsubsection{Push-Ups}

Participants assumed the front leaning rest position with feet $\leq 30 \mathrm{~cm}$ apart and began the push-up by bending at the elbows until the upper arms were at least parallel to the floor, before returning to the start position. Repetitions were not counted if the body did not form a generally straight line throughout the repetition or the arms were not fully extended at the end of the repetition. Rest was authorized using a front leaning position, but testing was terminated upon knee ground contact or the release of hand or foot ground contact. The number of successfully completed repetitions in the allotted 2 min was recorded [23].

\subsubsection{2 km Run (Two-Mile Run)}

Participants began behind the starting line and completed eight laps on the $400 \mathrm{~m}$ outdoor track at a self-selected pace. Participants were not allowed to be physically helped in any way (i.e., being pulled, pushed, and/or carried) and were required to remain on the track, or testing was terminated. The group's running clock began on 'go' and respective times were recorded as participants crossed the finish line [23].

These events were scored on a scale of 0 to 100 points based on table values for sex and age. Based on their APFT score, soldiers were later awarded an APFT mark in the range of 1-5 ( 1 being the worst (not passing), and 5 being excellent). The cut off values for APFT marks are: mark $1<150$ points; mark $2=150-180$ points; mark $3=181-220$ points; mark $4=221-270$ points; and mark $5 \geq 271$. Points below 50 for any part of the APFT would be automatically given mark 1 . We collected the results of the most recent APFT (testing was performed within two weeks of functional testing) that was administered according to the standard testing protocol.

\subsection{Functional Physical Fitness Testing (FPFT)}

FPFT, as shown in Figure 1, was performed in the gym of the SAF military post and included the SLHBT, countermovement jump (CMJ) testing with and without additional load, pull-ups, loaded prone plank test, and stork balance test (the results from this test were not used in further analysis, as we have shown in our previous work that this test was not demanding enough for the performance level of soldiers). All tests were conducted from 8 a.m. to 12 p.m.; a detailed explanation of all testing procedures is provided elsewhere [8]. For the reproducibility assessment, the SLHBT was performed according to the same instructions given in the larger sample, but the individuals repeated the test after one week, 
during which they were not allowed to specifically train hamstrings. The initial testing leg was randomly chosen for each individual and tested second upon re-test to minimize and control the possible learning effect.

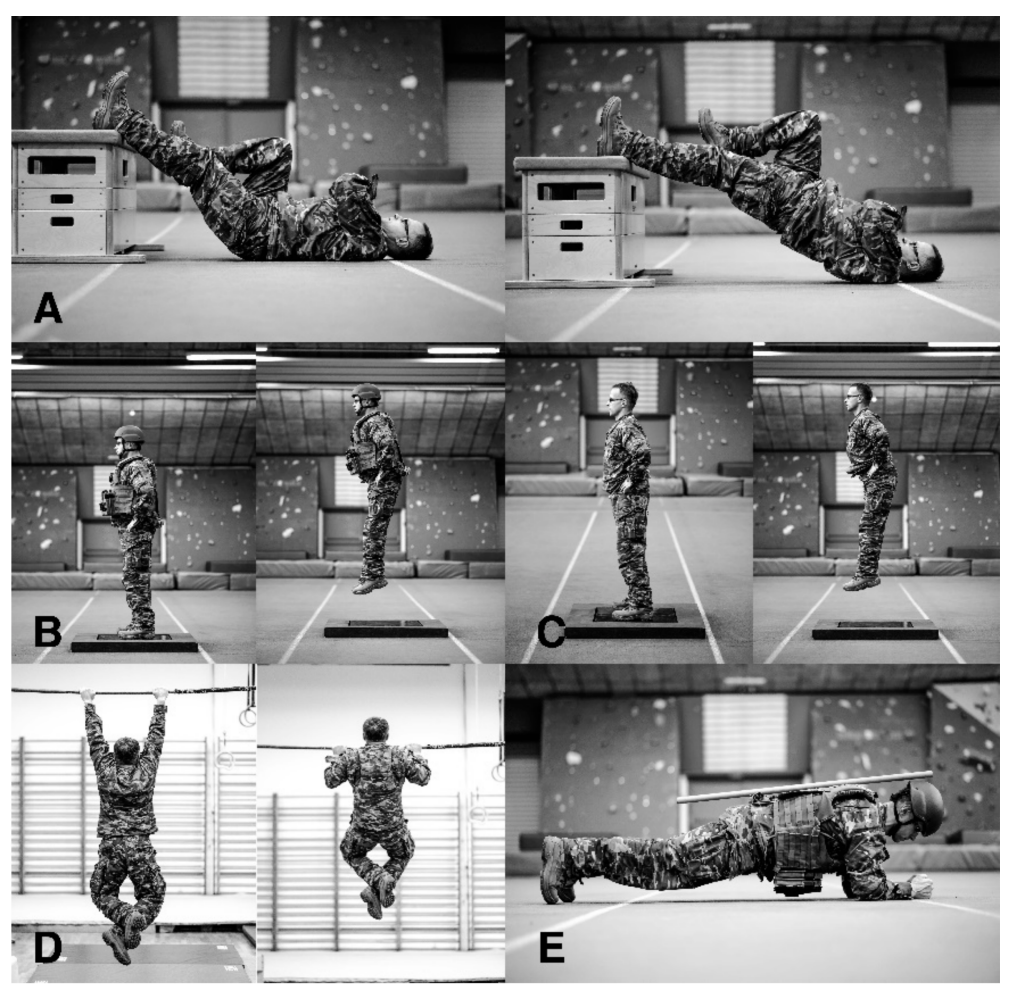

Figure 1. Functional physical fitness testing (FPFT). (A) SLHBT, (B) loaded countermovement jump, (C) countermovement jump, (D) pull-ups, (E) loaded prone plank test.

\subsubsection{Single Leg Hamstring Bridge Test (SLHBT)}

In this test, the individual lies down on the ground with one heel on a $60 \mathrm{~cm}$ high box (knee flexed to approximately $20^{\circ}$ and hip flexed to approximately $45^{\circ}$ ). The individual is then instructed to push down through the heel to lift their bottom off the ground while holding their arms crossed over their chest. Repetition is considered regular when the individual touches the ground and then extends their hip to $0^{\circ}$ without resting on the ground. This is a strength endurance hamstring test where the individual performs repetitions until exhaustion, and the test ends when: (1) technique becomes irregular, or (2) the individual cannot proceed with the test due to fatigue. The number of successful repetitions for each leg (right and left) is the main outcome measure of the test.

\subsubsection{Countermovement Jump (CMJ) Testing}

Two Kistler force platforms (Kistler 9286AA; Kistler Instrument Corp, Winterthur, Switzerland) with ARS software (S2P, Science to Practice, Ltd., Ljubljana, Slovenia) were set up parallel for each foot on one platform while performing a jump. The test started from an upright standing position with hands held on hips, making a preliminary downward movement by flexing at the knees and hips, then immediately extending the knees and hips again to jump vertically up off the ground. The CMJ test was performed in uniform and boots (unloaded CMJ), and then the same procedure was repeated with soldiers wearing body armour and a helmet (loaded CMJ). Under each testing condition, an individual had two jump trials, and the repetition with the highest jump was used for further analysis [8]. 


\subsubsection{Loaded Prone Plank Test}

For the prone plank test, individuals maintained a prone position in which their body mass was supported by the toes and forearms. The test was performed in full army uniform while wearing body armour and a helmet. Individuals were instructed to maintain a neutral position of the spine and pelvis and to breathe normally during testing. Each test was terminated when the individual was unable to maintain their posture or their pelvis moved up or down five or more centimetres. Each holding time was recorded using a stopwatch. The holding time (seconds) of the prone plank test was used for further analysis [8].

\subsubsection{Pull-Ups}

The starting position for pull-ups was with arms fully extended and locked in elbows, with an overhand grip, the body motionless, and feet off the floor. The individual then bent and crossed the knees over backwards from the starting position before pulling up over the bar until the chin cleared the top of the bar without any excessive body motion. The body was then lowered until arms were again fully extended or locked out. One complete pull-up was counted when the individual's arms were locked out. This procedure was repeated at the individual's own pace (rest between repetitions was allowed only in the full hang position) until the individual could no longer complete a full pull-up. The number of successful repetitions was used as the performance measure in this task [8].

\subsection{Data Analysis}

Categorical variables are displayed as numbers and percentages, and numeric variables are presented as means and standard deviations. All numeric variables were firstly checked for normality of distribution with the Shapiro-Wilk test. If not stated otherwise, all calculations were performed using SPSS statistical package version 25 (SPSS Inc, Chicago, IL, USA).

The agreement between measurements was assessed with the intraclass correlation coefficient $\left(\mathrm{ICC}_{2,1}\right)$ and with the $95 \%$ confidence interval $(95 \% \mathrm{CI})$ for ICC. Calculations were performed using SPSS based on a mean rating $(\mathrm{k}=2)$, absolute agreement, 2-way mixedeffects model. ICC values were interpreted according to recent guidelines [24]. Absolute and relative measurement error was assessed with a standard error of measurement (SEM) and with the SEM \%, respectively, with the additional calculation of smallest real difference (SRD) and Bland-Altman analysis [25]. The coefficient of variation (CV) was calculated as a ratio between the standard deviation and the mean.

The APFT mark (1-5) was used as the outcome variable in the ROC analysis, where marks 4 and 5 were joined to form a new mark (good to excellent baseline fitness), as opposed to marks 1-3 (poor to moderate baseline fitness). The ROC analysis was then carried out to examine the discriminatory ability of the SLHBT to predict APFT passing score $>4$ as an objective measure of good baseline fitness quantified by the area under the curve (AUC) as the diagnostic power of a test. Optimal sensitivity and specificity were the values yielding maximum AUC from the ROC curves. The optimal value was considered the cut-off point with the fewest false positives and negatives [26]. MedCalc 16.8.4 statistical software (Ostend, Belgium) was used for ROC analyses.

Following the cut-off point calculation for the SLBHT, we introduced a new categorical variable based on that cut-off point and performed an analysis of covariance (ANCOVA) where SLBHT performance was an independent predictor of overall physical performance (based on performance on all tests) and body mass was used as a covariate. A partial eta square was calculated to evaluate the effect size. The significance level was set at $p$-value $<0.05$.

\section{Results}

The results of the reproducibility of the SLHBT in soldiers are presented in Table 1. Both sides' ICC values were moderate to high, indicating good reproducibility of this test. The 
same was true for the standard error of measurement, which was very low and presented as less than $5 \%$ of the mean. The Bland-Altman plot is depicted in Figure 2. Based on these results, we conclude that the SLHBT has good reproducibility when performed in military settings.

Table 1. Reproducibility parameters of single leg hamstring bridge (SLHB) test in soldiers $(\mathrm{N}=20)$.

\begin{tabular}{cccccccc}
\hline Side & ICC & 95\% CI for ICC & CV \% & SEM (\#) & SEM \% & SRD (\#) & SRD (\%) \\
\hline Left & 0.898 & $(0.768,0.957)$ & $8.28 \%$ & 2 & $3.72 \%$ & 4 & $10 \%$ \\
Right & 0.901 & $(0.774,0.958)$ & $6.78 \%$ & 2 & $4.58 \%$ & 5 & $13 \%$ \\
\hline
\end{tabular}

ICC—intraclass correlation coefficient; CV—coefficient of variance; SEM-standard error of measurement; (\#)number of repetitions; SRD—smallest real difference; CI: confidence interval.
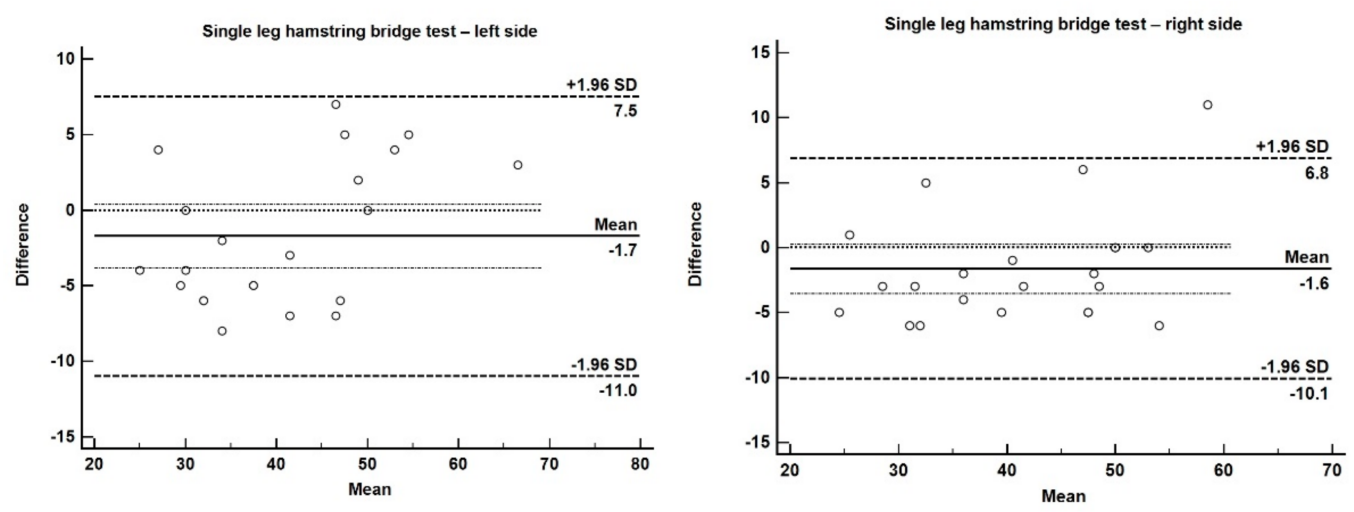

Figure 2. Bland-Altman plots for the single leg hamstring bridge test for the left and right side.

Receiver operating curve analysis (ROC) was carried out to examine the discriminatory ability of the SLHBT to predict APFT passing score $\geq 4$ as an objective measure of goodexcellent baseline fitness quantified by the area under the curve (AUC) as the diagnostic power of a test. ROC analysis (Figure 3) showed a significant accuracy of the SLHBT in discriminating between soldiers with good and poor baseline fitness (AUC 0.756, 95\% CI 0.687 to $0.817, p<0.0001$ ). The SLHBT cut-off level associated with belonging to a good baseline fitness group was $>20$ repetitions (optimal pair of sensitivity and specificity was 81.2 and 59.3, respectively).

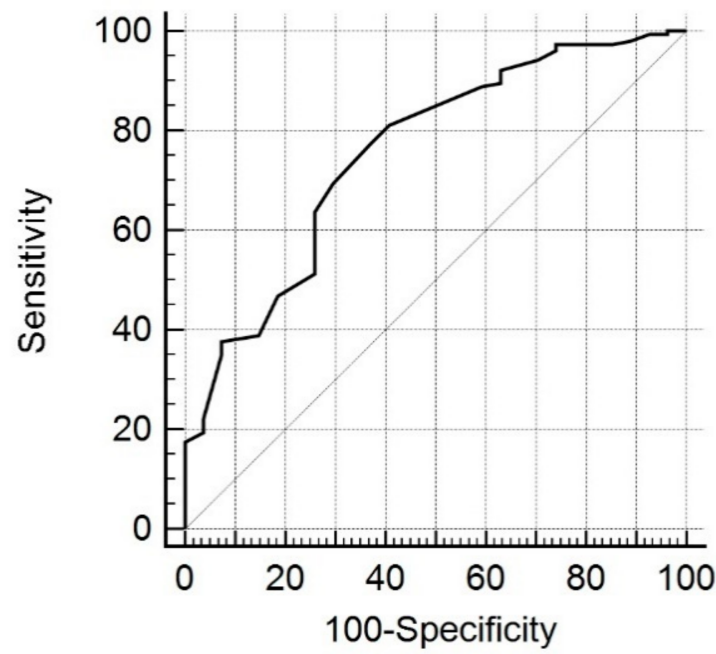

Figure 3. The receiver operating curve for predicting baseline fitness using the single leg hamstring bridge test. 
There were statistically significant differences in dependent variables between the groups of soldiers with different SLBHT performance ( $\geq 21$ vs. $\leq 20$ repetitions; Table 2 ) when adjusted for body mass. It should be noted that a non-significant difference was noted for CMJ $(p=0.229)$, loaded CMJ $(p=0.49)$ and push-ups $(p=0.071)$, while differences in all other tests (loaded plank test, pull-ups, trunk raises, two-mile run)were significant with medium size effects according to partial eta square value.

Table 2. Differences in the physical performance of soldiers with different hamstring strengths.

\begin{tabular}{|c|c|c|c|c|c|c|c|c|}
\hline Fitness Test & $\begin{array}{c}\text { SLHBT } \\
\text { Performance }\end{array}$ & $\mathbf{N}$ & Mean & $\mathrm{SD}$ & $\mathbf{F}$ & $\begin{array}{c}\text { Mean } \\
\text { Difference }\end{array}$ & Sig. & $\begin{array}{c}\text { Partial Eta } \\
\text { Squared }\end{array}$ \\
\hline \multirow{2}{*}{$\begin{array}{l}\text { Plank test } \\
\text { (seconds) }\end{array}$} & Weak & 45 & 97 & 42 & \multirow{2}{*}{12.567} & \multirow{2}{*}{-32} & \multirow{2}{*}{0.001} & \multirow{2}{*}{0.07} \\
\hline & Good & 136 & 129 & 49 & & & & \\
\hline \multirow{2}{*}{ Pull-ups (\#) } & Weak & 45 & 3 & 3 & \multirow{2}{*}{12.575} & \multirow{2}{*}{-3} & \multirow{2}{*}{$<0.001$} & \multirow{2}{*}{0.07} \\
\hline & Good & 136 & 6 & 4 & & & & \\
\hline \multirow{2}{*}{$\mathrm{CMJ}(\mathrm{cm})$} & Weak & 45 & 27.0 & 4.3 & \multirow{2}{*}{1.459} & \multirow{2}{*}{-1.2} & \multirow{2}{*}{0.229} & \multirow{2}{*}{0.008} \\
\hline & Good & 136 & 28.2 & 4.1 & & & & \\
\hline \multirow{2}{*}{ Loaded CMJ (cm) } & Weak & 45 & 24.5 & 4.3 & \multirow{2}{*}{0.478} & \multirow{2}{*}{-0.69} & \multirow{2}{*}{0.490} & \multirow{2}{*}{0.003} \\
\hline & Good & 136 & 25.2 & 4.4 & & & & \\
\hline \multirow{2}{*}{ Push-ups (\#) } & Weak & 45 & 66 & 12 & \multirow{2}{*}{3.306} & \multirow{2}{*}{-6} & \multirow{2}{*}{0.071} & \multirow{2}{*}{0.02} \\
\hline & Good & 136 & 70 & 10 & & & & \\
\hline \multirow{2}{*}{ Trunk raises (\#) } & Weak & 45 & 67 & 13 & \multirow{2}{*}{10.56} & \multirow{2}{*}{-8} & \multirow{2}{*}{0.001} & \multirow{2}{*}{0.06} \\
\hline & Good & 136 & 75 & 11 & & & & \\
\hline \multirow{2}{*}{ Two-mile run (min) } & Weak & 45 & $15: 31$ & $1: 19$ & \multirow{2}{*}{15.353} & \multirow{2}{*}{$0: 59$} & \multirow{2}{*}{$<0.001$} & \multirow{2}{*}{0.08} \\
\hline & Good & 136 & $14: 31$ & $1: 12$ & & & & \\
\hline
\end{tabular}

SLBHT performance: good $\geq 21$ repetition; weak $\leq 20$ repetitions. (\#)—number of repetitions. CMJ—countermovement jump.

\section{Discussion}

The main finding of our study is that the SLHBT shows acceptable reproducibility in a military setting and has moderate predictive validity to discriminate between soldiers with poor and good overall physical fitness performance using a cut-off value of 20 repetitions.

In a previous study, the SLHBT was performed on rugby players and showed good to excellent reproducibility with intra-rater intraclass correlation coefficient (ICC) values in the range of $0.77-0.89$ [19]. This is in line with our results, where the ICC range was $0.77-0.96$, indicating slightly better results. The usefulness of the SLHBT was additionally confirmed by low SEM \% (the limit for the smallest change that indicates a real improvement for a group of participants following given intervention; e.g., exercise training) and SRD \% values (the smallest change that indicates a real improvement for a single participant) [27], and no signs of systematic error on Bland-Altman plots.

Our research group was the first to report performance (including percentile ranks) on this test in the military population [8], where male soldiers have reached 30 and 27 repetitions for the right and left leg, respectively, which was comparable with healthy semi-elite Australian football players who reached 26 repetitions [19]. The original test authors have suggested three cut-off values of 20,21-30, and $>30$ repetitions for poor, average, and good hamstring strength, respectively. They have also reported that athletes with poor hamstring strength ( $<20$ reps) have an increased risk for hamstring strain injury, indicating the possible importance of this test to screen and identify athletes at risk and to evaluate their physical readiness for return to sport. Our ROC analysis has shown that a cut-off point of 20 repetitions can be used in a military setting if we want to discriminate between soldiers with poor and good overall physical fitness performance (as measured by APFT and FPFT). The AUC in our study was $0.756(p<0.001)$ and knowing that a 
diagnostic test with AUC value equal to 1 is perfectly accurate, whereas a value equal to 0.5 has no discrimination power, we may conclude that this value corresponds to a large effect size [28]. Furthermore, with the simple inclusion of force plate measurement, this test can be easily transformed into a more thorough and precise isometric posterior chain test [29] that, unlike an isokinetic test, can also be performed in the field. The SLHBT requires little equipment and resources, can simultaneously accommodate testing of several participants [30], and can detect potential bilateral asymmetries.

It seems that good hamstring performance is a characteristic of soldiers with generally good overall physical performance, as they performed better on all physical fitness tests (CMJ and push-ups were non-significant, but have shown the same trend). It may be that soldiers at the lower level of overall physical fitness executed the specific training program only to achieve better results on the APFT (as this test is obligatory for them), while on the other hand, soldiers with good overall physical performance (e.g., who were not worried about passing the APFT successfully) did general functional fitness training with a broad range of diverse physical tasks. It was shown in previous studies [31] that a generalized approach to training could also improve soldiers' scores on the APFT without a specific focus on APFT tasks. This could at least in part explain how hamstring performance could be related to, e.g., pull-up and/or push-up performance $(p=0.071)$. Additionally, there is a functional-anatomical connection between the hamstring muscles (biceps femoris muscle; BF) and the sacrotuberous ligament [32] that may also explain the impact of hamstring performance on other upper body exercises where the trunk needs to be stabilized. Furthermore, it has been shown in elite soccer players that strengthening of the hamstrings can influence some explosive activities such as short $5 \mathrm{~m}$ and $10 \mathrm{~m}$ sprint times and maximal CMJ height [33], showing that hamstring strength can have an influence on other physical performance parameters. Nevertheless, the different nature of the motor test must be acknowledged. For example, the CMJ evaluates the elastic-explosive force, while the SLHBT evaluates unilateral resistance strength, which is why it refers to two different manifestations of producing force. Additionally, EMG (electromyography) studies have shown that trunk muscle activities (i.e., internal oblique, rectus abdominis, erector spinae) are significantly greater during single-leg lift bridge exercise and that such effects can be increased even more with the performance of this exercise on unstable surfaces [34]. The largest effect size was noticed for the difference in a two-mile run, where soldiers with good hamstring strength, which is associated with better running performance [35], were almost 1 min faster than their counterparts with weak hamstring strength.

The single leg bridge exercise and test, as a closed kinetic chain exercise [34], activate the hamstring, gluteus maximus (GM) and gluteus medius muscles [20] with the single leg support adding to the rotational torque in the trunk to additionally increase the activation of the trunk muscles to maintain neutral lumbar position [36]. Higher hamstring performance is also important [37] in cases where the hamstring muscle, as GM main synergists [38], needs to take over because of reduced strength or activation of the GM muscle [39,40]. Performing deadlifts, front and back squats, lunges etc. (as weight lifting exercises in the functional fitness training program) could also result in better achievement in single leg bridge tests, as these exercises activate gluteal muscles and hamstrings [41,42], which are also recruited in the single leg bridge task. Incorporating these exercises in military training to recruit and train the muscles of the posterior chain (the hamstrings and gluteal group) may minimize overuse in the lumbar extensors (erector spinae) while reducing the likelihood for injury and enhancing muscular firing patterns [43]. The importance of increased hamstring strength has also been reported as an important factor in lowering knee pain in military settings like road marching or hill climbing [44]. The SLHBT could be of use in the initial physical conditioning screening and its result could help strength and conditioning trainers to better plan the training of soldiers and to test the progress in between and at the end of a training cycle.

We acknowledge some limitations of this study. The SLHBT measures strength endurance and not maximal strength, and the data to compare SLHBT scores are limited to 
the research of our research group as the SLHBT has not been used in military settings. To conclude, single leg bridge performance could be a potentially important addition to the standard APFT testing battery and additional controlled studies are needed to explain our observational cross-sectional findings.

\section{Conclusions}

The SLHBT could be a good candidate test for the military population as the receiver operating curve (ROC) analysis showed the ability of the SLHBT to discriminate between soldiers with poor and good baseline fitness. The SLHBT is a simple and affordable test that could be of use in the initial physical conditioning screening and its result could help strength and conditioning trainers to better plan the training of soldiers and to test the progress in between and at the end of a training cycle. Its values could be used for performance and preventive guidelines for military personnel. Also, the SLHBT results from this study could be used in the future for creating normative values for the military population.

Author Contributions: Conceptualization, V.H., B.K. and P.P.; methodology, V.H., P.P. and E.D.; software, B.K. and J.Š.; validation, B.K., V.H., P.P. and J.Š.; formal analysis, V.H.; investigation, J.Š., B.K., P.P. and V.H.; resources, D.K., E.D. and J.V.; data curation, V.H. and J.Š.; writing—original draft preparation, V.H., J.Š. and P.P.; writing—review and editing, V.H., J.Š. and P.P.; visualization, V.H. and J.Š.; supervision, V.H.; project administration, V.H. and B.K.; funding acquisition, J.V. and D.K. All authors have read and agreed to the published version of the manuscript.

Funding: This research received no external funding.

Institutional Review Board Statement: The study was conducted according to the guidelines of the Declaration of Helsinki, and was approved by the Faculty of Sport, University of Ljubljana Ethical Board (No. 454/2017) and Headquarters of the SAF (No. 630-1/2016-3).

Informed Consent Statement: Informed consent was obtained from all subjects involved in the study.

Data Availability Statement: The data presented in this study are available on request from the corresponding author.

Acknowledgments: This work was supported by the Slovenian Research Agency [P5-0147].

Conflicts of Interest: The authors declare no conflict of interest.

\section{References}

1. Schache, A.G.; Dorn, T.W.; Wrigley, T.V.; Brown, N.A.T.; Pandy, M.G. Stretch and activation of the human biarticular hamstrings across a range of running speeds. Eur. J. Appl. Physiol. 2013, 113, 2813-2828. [CrossRef]

2. Ishøi, L.; Aagaard, P.; Nielsen, M.F.; Thornton, K.B.; Krommes, K.K.; Hölmich, P.; Thorborg, K. The Influence of Hamstring Muscle Peak Torque and Rate of Torque Development for Sprinting Performance in Football Players: A Cross-Sectional Study. Int. J. Sports Physiol. Perform. 2019, 14, 665-673. [CrossRef]

3. López-Miñarro, P.; Muyor, J.; Belmonte, F.; Alacid, F. Acute Effects of Hamstring Stretching on Sagittal Spinal Curvatures and Pelvic Tilt. J. Hum. Kinet. 2012, 31. [CrossRef]

4. De la Motte, S.J.; Lisman, P.; Gribbin, T.C.; Murphy, K.; Deuster, P.A. Systematic Review of the Association Between Physical Fitness and Musculoskeletal Injury Risk. J. Strength Cond. Res. 2019, 33, 1723-1735. [CrossRef]

5. Jones, B.H.; Cowan, D.N.; Tomlinson, J.P.; Robinson, J.R.; Polly, D.W.; Frykman, P.N. Epidemiology of injuries associated with physical training among young men in the army. Med. Sci. Sports Exerc. 1993, 25, 197-203. [CrossRef]

6. Knapik, J.J.; Sharp, M.A.; Canham-Chervak, M.; Hauret, K.; Patton, J.F.; Jones, B.H. Risk factors for training-related injuries among men and women in basic combat training. Med. Sci. Sports Exerc. 2001, 33, 946-954. [CrossRef] [PubMed]

7. Keenan, K.A.; Wohleber, M.F.; Perlsweig, K.A.; Baldwin, T.M.; Caviston, M.; Lovalekar, M.; Connaboy, C.; Nindl, B.C.; Beals, K. Association of prospective lower extremity musculoskeletal injury and musculoskeletal, balance, and physiological characteristics in Special Operations Forces. J. Sci. Med. Sport 2017, 20, S34-S39. [CrossRef] [PubMed]

8. Šimenko, J.; Kovčan, B.; Pori, P.; Vodičar, J.; Vodičar, M.; Hadžić, V. The Relationship between Army Physical Fitness and Functional Capacities in Infantry Members of the Slovenian Armed Forces. J. Strength Cond. Res. 2019. [CrossRef]

9. Rezasoltani, Z.; Dehghan, F.; Azizan, A.; Dadarkhah, A.; Yadegarian, F. The Frequency of Knee-Joint Injuries Caused by Sports Activities Among the Armed Forces Personnel. J. Arch. Mil. Med. 2016, 4. [CrossRef]

10. Bourne, M.N.; Williams, M.D.; Opar, D.A.; Al Najjar, A.; Kerr, G.K.; Shield, A.J. Impact of exercise selection on hamstring muscle activation. Br. J. Sports Med. 2017, 51, 1021-1028. [CrossRef] 
11. Shield, A.; Bourne, M. Optimising Hamstring Strength and Function for Performance After Hamstring Injury. In Prevention and Rehabilitation of Hamstring Injuries; Springer: Cham, Switzerland, 2020; pp. 283-313.

12. Schmitt, B.; Wollin, M.; Tyler, T.; Whiteley, R.; Thorborg, K. Clinical Assessment of Hamstring Injury and Function. In Prevention and Rehabilitation of Hamstring Injuries; Springer: Cham, Switzerland, 2020; pp. 199-223.

13. Van Dyk, N.; Bahr, R.; Burnett, A.F.; Whiteley, R.; Bakken, A.; Mosler, A.; Farooq, A.; Witvrouw, E. A comprehensive strength testing protocol offers no clinical value in predicting risk of hamstring injury: A prospective cohort study of 413 professional football players. Br. J. Sports Med. 2017, 51, 1695-1702. [CrossRef]

14. Mentiplay, B.F.; Perraton, L.G.; Bower, K.J.; Adair, B.; Pua, Y.-H.; Williams, G.P.; McGaw, R.; Clark, R.A. Assessment of Lower Limb Muscle Strength and Power Using Hand-Held and Fixed Dynamometry: A Reliability and Validity Study. PLoS ONE 2015, 10, e0140822. [CrossRef]

15. Mondin, D.; Owen, J.A.; Negro, M.; D'Antona, G.; D'Antona, G. Validity and Reliability of a Non-invasive Test to Assess Quadriceps and Hamstrings Strength in Athletes. Front. Physiol. 2018, 9. [CrossRef] [PubMed]

16. Wollin, M.; Purdam, C.; Drew, M.K. Reliability of externally fixed dynamometry hamstring strength testing in elite youth football players. J. Sci. Med. Sport 2016, 19, 93-96. [CrossRef]

17. Lodge, C.; Tobin, D.; O'Rourke, B.; Thorborg, K. Reliability and Validity of a New Eccentric Hamstring Strength Measurement Device. Arch. Rehabil. Res. Clin. Transl. 2020, 2, 100034. [CrossRef]

18. Lee, J.W.Y.; Cai, M.-J.; Yung, P.S.H.; Chan, K.-M. Reliability, Validity, and Sensitivity of a Novel Smartphone-Based Eccentric Hamstring Strength Test in Professional Football Players. Int. J. Sports Physiol. Perform. 2018, 13, 620-624. [CrossRef] [PubMed]

19. Freckleton, G.; Cook, J.; Pizzari, T. The predictive validity of a single leg bridge test for hamstring injuries in Australian rules football players. Br. J. Sports Med. 2014, 48, 713-717. [CrossRef]

20. Lehecka, B.J.; Edwards, M.; Haverkamp, R.; Martin, L.; Porter, K.; Thach, K.; Sack, R.J.; Hakansson, N.A. Building a Better Gluteal Bridge: Electromyographic Analysis of Hip Muscle Activity During Modified Single-Leg Bridges. Int. J. Sports Phys. Ther. 2017, 12, 543-549.

21. Knapik, J.J.; East, W.B. History of United States Army physical fitness and physical readiness training. US Army Med. Dep. J. 2014, 5-19. Available online: https://www.researchgate.net/profile/Courtenay_Dunn-Lewis/publication/261409161_Relationships_ of_Physical_Performance_Tests_to_Military-relevant_Tasks_in_Women/links /0a85e5359983616cdd000000.pdf\#page=7 (accessed on 17 February 2021).

22. Bigelman, K.A.; East, W.B.; Thomas, D.M.; Turner, D.; Hertling, M. The New Army Combat Fitness Test: An Opportunity to Improve Recruitment and Retainment. Obesity 2019, 27, 1772-1775. [CrossRef] [PubMed]

23. Draicchio, C.; Martin, J.R.; Fyock-Martin, M.B.; Merrigan, J.J. Retrospective Cohort Analysis of the Army Physical Fitness Test and the Occupational Physical Assessment Test in Reserve Officer Training Corps Cadets: A Brief Report. Mil. Med. 2020, 185, e937-e943. [CrossRef] [PubMed]

24. Koo, T.K.; Li, M.Y. A Guideline of Selecting and Reporting Intraclass Correlation Coefficients for Reliability Research. J. Chiropr. Med. 2016, 15, 155-163. [CrossRef]

25. Kambič, T.; Lainščak, M.; Hadžić, V. Reproducibility of isokinetic knee testing using the novel isokinetic SMM iMoment dynamometer. PLoS ONE 2020. [CrossRef]

26. Habibzadeh, F.; Habibzadeh, P.; Yadollahie, M. On determining the most appropriate test cut-off value: The case of tests with continuous results. Biochem. Med. 2016, 26, 297-307. [CrossRef]

27. Beckerman, H.; Roebroeck, M.E.; Lankhorst, G.J.; Becher, J.G.; Bezemer, P.D.; Verbeek, A.L. Smallest real difference, a link between reproducibility and responsiveness. Qual. Life Res. 2001, 10, 571-578. [CrossRef] [PubMed]

28. Rice, M.E.; Harris, G.T. Comparing effect sizes in follow-up studies: ROC area, Cohen's d, and r. Law Hum. Behav. 2005, 29, 615-620. [CrossRef] [PubMed]

29. McCall, A.; Nedelec, M.; Carling, C.; Le Gall, F.; Berthoin, S.; Dupont, G. Reliability and sensitivity of a simple isometric posterior lower limb muscle test in professional football players. J. Sports Sci. 2015, 33, 1298-1304. [CrossRef] [PubMed]

30. Rey, E.; Paz-Domínguez, Á.; Porcel-Almendral, D.; Paredes-Hernández, V.; Barcala-Furelos, R.; Abelairas-Gómez, C. Effects of a 10-Week Nordic Hamstring Exercise and Russian Belt Training on Posterior Lower-Limb Muscle Strength in Elite Junior Soccer Players. J. Strength Cond. Res. 2017, 31, 1198-1205. [CrossRef] [PubMed]

31. Paine, J.; Uptgraft, J.; Wylie, R. U.S. Army CrossFit Study: May 2010. CrossFit J. 2010, 3, 72. Available online: http:/ /journal. crossfit.com/2010/09/us-army-crossfit-study-may-2010.tpl (accessed on 23 December 2020).

32. Vleeming, A.; Stoeckart, R.; Snijders, C.J. The sacrotuberous ligament: A conceptual approach to its dynamic role in stabilizing the sacroiliac joint. Clin. Biomech. 1989, 4, 201-203. [CrossRef]

33. Krommes, K.; Petersen, J.; Nielsen, M.B.; Aagaard, P.; Hölmich, P.; Thorborg, K. Sprint and jump performance in elite male soccer players following a 10-week Nordic Hamstring exercise Protocol: A randomised pilot study. BMC Res. Notes 2017, 10, 669. [CrossRef]

34. Yoon, J.-O.; Kang, M.-H.; Kim, J.-S.; Oh, J.-S. Effect of modified bridge exercise on trunk muscle activity in healthy adults: A cross sectional study. Braz. J. Phys. Ther. 2018, 22, 161-167. [CrossRef] [PubMed]

35. Sundby, Ø.H.; Gorelick, M.L.S. Relationship between functional hamstring: Quadriceps ratios and running economy in highly trained and recreational female runners. J. Strength Cond. Res. 2014, 28, 2214-2227. [CrossRef] [PubMed] 
36. García-Vaquero, M.P.; Moreside, J.M.; Brontons-Gil, E.; Peco-González, N.; Vera-Garcia, F.J. Trunk muscle activation during stabilization exercises with single and double leg support. J. Electromyogr. Kinesiol. 2012, 22, 398-406. [CrossRef]

37. Buckthorpe, M.; Wright, S.; Bruce-Low, S.; Nanni, G.; Sturdy, T.; Gross, A.S.; Bowen, L.; Styles, B.; Della Villa, S.; Davison, M.; et al. Recommendations for hamstring injury prevention in elite football: Translating research into practice. Br. J. Sports Med. 2019, 53, 449-456. [CrossRef] [PubMed]

38. Mills, M.; Frank, B.; Goto, S.; Blackburn, T.; Cates, S.; Clark, M.; Aguilar, A.; Fava, N.; Padua, D. Effect of restricted hip flexor muscle length on hip extensor muscle activity and lower extremity biomechanics in college-aged female soccer players. Int. J. Sports Phys. Ther. 2015, 10, 946-954. [PubMed]

39. Schuermans, J.; Danneels, L.; Van Tiggelen, D.; Palmans, T.; Witvrouw, E. Proximal Neuromuscular Control Protects Against Hamstring Injuries in Male Soccer Players: A Prospective Study with Electromyography Time-Series Analysis during Maximal Sprinting. Am. J. Sports Med. 2017, 45, 1315-1325. [CrossRef]

40. Sugiura, Y.; Saito, T.; Sakuraba, K.; Sakuma, K.; Suzuki, E. Strength Deficits Identified with Concentric Action of the Hip Extensors and Eccentric Action of the Hamstrings Predispose to Hamstring Injury in Elite Sprinters. J. Orthop. Sports Phys. Ther. 2008, 38, 457-464. [CrossRef]

41. Fauth, M.L.; Garceau, L.R.; Lutsch, B.; Gray, A.; Szalkowski, C.; Wurm, B.; Ebben, W.P. Hamstrings, Quadriceps, and Gluteal Muscle Activation During Resistance Training Exercises. In Proceedings of the 28 International Conference on Biomechanics in Sports, Marquette, MI, USA, 19-23 July 2010.

42. Wu, H.-Y.; Chen, J.-K.; Chen, I.-S.; Zhuo, H.-H. Ranking universities based on performance evaluation by a hybrid MCDM model. Measurement 2012, 45, 856-880. [CrossRef]

43. Turner, A. Strength and Conditioning for British Soldiers. Strength Cond. J. 2016, 38, 59-68. [CrossRef]

44. Knapik, J.J.; Reynolds, K.L.; Harman, E. Soldier Load Carriage: Historical, Physiological, Biomechanical, and Medical Aspects. Mil. Med. 2004, 169, 45-56. [CrossRef] 